\title{
PEMANFAATAN PEKARANGAN RUMAH DAN LIMBAH BOTOL PLASTIK DENGAN METODE TANAM HIDROPONIK DI RT.12 KELURAHAN JALAN GEDANG KECAMATAN GADING CEMPAKA KOTA BENGKULU
}

\author{
R. Lubis ", A. Cahaya, R. Pratama \\ ${ }^{1)}$ Program Studi Pendidikan Biologi, Fakultas Keguruan dan Ilmu Pendidikan, Universitas \\ Muhammadiyah Bengkulu
}

\begin{abstract}
ABSTRAK
Meningkatnya populasi penduduk menyebabkan terjadinya perluasan lahan pemukiman dan usaha. Hal ini menimbulkan permasalahan baru bagi masyarakat yaitu penyempitan lahan pertanian bagi penduduk sementara kebutuhan masyarakat akan sumber makanan terutama sayur dan buah terus meningkat. Salah satu solusi yang diberikan terkait sempitnya lahan pertanian adalah dengan merubah pola pertanian dari awalnya berbasis tanah menjadi berjadi berbasis air (hidroponik). Beberapa kajian literatur menunjukkan bahwa sistem hidroponik dapat menjadi solusi atas keterbatasan lahan pertanian dan bahkan kualitas sayur dan buah yang dihasilkan melalui hidroponik dapat dioptimalkan dengan baik. Kegiatan pengabdian ini dilakukan dalam bentuk penyuluhan dan sosialisasi kepada masyarakat tentang: a). Keunggulan dan kelemahan sistem hidroponik; b). Membuat sistem hidroponik sederhana diperkarangan rumah dengan menggunakan botol plastik; c). Pengelolaan nutrisi yang benar dalam sistem hidroponik.
\end{abstract}

Keyword: hidroponik, botol plastik, nutrisi

\section{PENDAHULUAN}

Rukun Tetangga (RT) 12 merupakan salah satu RT yang ada di RW.05 Kelurahan Jalan Gedang Kecamatan Jalan Gedang Kota Bengkulu dan merupakan salah satu RT yang sangat pesat perkembangannya. Jumlah penduduk di RT. 12 ini adalah 180 jiwa, yang terdiri dari laki-laki 80 jiwa, dan perempuan 100 jiwa. Rukun Tetangga 12 yang letaknya cukup dekat dengan Ibukota Provinsi, diprogramkan untuk pengembangan pemukiman penduduk sehingga di RT ini ditemukan banyaknya pembangunan perumahan penduduk dengan type yang beragam, baik itu dibangun oleh developer atau perusahan-perusahan properti mandiri yang menjadikan RT ini sebagai RT yang padat penduduk dengan berdirinya perumahan-perumahan dengan luas lahan yang terbatas.

Lahan yang sangat terbatas dengan bangunan yang terbatas pula, sehingga para pemilik rumah berusaha untuk mengembangkan rumah tersebut agar terlihat lebih besar dan luas, akibatnya pekarangan rumah yang tertinggal sempit sekali bahkan ada rumah yang tidak memiliki pekarangan lagi. Potensi pekarangan sempit di perumahan seperti inilah yang akan diberdayakan, sehingga dari pekarangan sempit tersebut dapat dihasilkan sayuran yang merupakan kebutuhan pangan bagi masyarakat tempatan dapat terpenuhi.

Pekarangan merupakan lahan terbuka yang dapat dimanfaatkan, dan memiliki arti yang sangat penting bagi kehidupan masyarakat. Sesempit apapun pekarangan tersebut, apabila dikelola dengan baik akan menghasilkan sesuatu yang bernilai tinggi. Pekarangan yang sempit dapat dimanfaatkan secara efisien untuk berbagai hal, seperti kegiatan yang akan dilakukan ini yaitu mengelola sedemikian rupa pekarangan sempit untuk pembudidayaan. 
Realisasi dari hal tersebut di atas adalah dengan mengoptimalkan pemakaian lahan pekarangan sempit secara efisien dengan sistem hidroponik yang memanfaatkan botol plastik bekas air mineral yang disusun sedemikian rupa sehingga populasi tanaman jauh lebih banyak bila dibandingkan budidaya sistem konvensional. Berdasarkan analisis situasi tersebut, maka perlu adanya usaha memanfaatkan setiap jengkal pekarangan yang tersisa untuk budidaya tanaman sehingga produktivitas pekarangan dapat ditingkatkan untuk menghasilkan pangan yang sehat bagi keluarga.

\section{METODE KEGIATAN}

Metode yang dilakukan dalam pelaksanaan penyuluhan ini adalah sosialisasi dengan cara memberikan materi tentang metode hidroponik dan praktek langsung pembuatan hidroponik dengan media botol bekas. Prosedur praktek Proses pembuatan media untuk berhidroponik menggunakan botol-botol air mineral bekas yang sudah tidak terpakai yaitu sebagai berikut :

a. siapkan botol bekas air mineral 1500 ml kemudian potong pakai pisau atau carter menjadi 2 bagian. Potong kain planel dengan panjang $10 \mathrm{~cm}$ dan lebar $2 \mathrm{~cm}$. Potong rockwool atau busa membentuk kubus dengan sisi $2 \mathrm{~cm}$. Setelah semua peralatan dipersiapakan, selanjutnya pada bagian atas botol air mineral yang sudah dipotong menjadi 2 bagian, kemudian di sayat dengan menggunakan pisau untuk membentuk lubang yang bertujuan untuk menaruh kain planel dan untuk menaruh rockwool atau busa. Bagian atas botol mineral yang sudah saip kemudian di satukan dengan ujung atas terbalik dan dipasang hingga membentuk seperti tabung.

b. Pembuatan larutan nutrisi yaitu dengan melarutkan pupuk A dan pupuk B yang yang sudah ada kedalam botol air mineral sesuai takaran dan petunjuk pada pupuk. Setiap $5 \mathrm{ml}$ larutan pupuk A dan Pupuk B di campur kedalam 1 liter air dan dicampur.

c. Cara penanaman bibit sayuran maupun buah dengan cara yaitu diambil 1 biji bibit kemudian diletakkan pada rockwol atau busa pada media yang telah disiapkan, selanjutnya isi media yang telah dibuat dengan larutan yang sudah dibuat juga. Biarkan sampai beberapa hari kemudian hingga tanaman tumbuh dengan baik. Jika sumber nutrisi pada media habis isi kembali dengan menambah air nutrisi atau pupuk $\mathrm{AB}$ mix.

\section{HASIL DAN PEMBAHASAN}

Langkah awal dalam melakukan penyuluhan ini adalah dengan melakukan sosialisasi pentingnya hidroponik dan besarnya manfaat hidroponik bagi masyarakat. Menurut Barbosa et al., (2015) Terdapat banyak keunggulan dengan melaksanakan hidroponik dipekarangan rumah, beberapa diantaranya yaitu: a). Pemanfaatan lahan dan air menjadi lebih efisien untuk tanaman; b). Hidroponik dapat didesain sebagai sumber pasokan makanan selama satu tahun; c). Jika dikelola dengan baik, sistem Hidroponik dapat menjadi sumber pendapatan masyarakat. Selain tiga keunggulan tersebut, beberapa kelebihan lain yang juga diperoleh dengan sistem hidroponik yaitu menghasilkan produk berkualitas dan kuantitas tinggi (Rosliani \& Sumarni, 2005), dapat dikembangkan pada lahan yang sangat sempit dan tanaman yang dibudidayakan jarang terkena hama dikarenakan lingkungan dan nutrisi yang terkontrol. Banyaknya manfaat dan keuntungan yang diberikan oleh hidroponik seharusnya membuat masyarakat tertarik dan berminat untuk mengembangkannya di pekarangan rumah masing-masing.

Terdapat beberapa jenis tanaman yang dapat dibudidayakan melalui sistem hidroponik, seperti jagung (Janda, Szalai, \& Tari, n.d.), tomat (Wasonowati, n.d.), mentimun, cabai, terong, stroberi, selada 
(Barbosa et al., 2015; Mas'ud, 2009) dan pakchoi (Perwtasari, Tripatmasari, \& Wasonowati, n.d.). Selain jenis sayuran, tanaman hidroponik juga dapat digunakan pada tanaman lain, seperti bunga, buahbuahan dan bahkan umbi-umbian (Roidah, 2014). Sejauh ini pemanfaatan sistem hidroponik banyak digunakan sebagai media tumbuh sayur dan buah-buahan dikarenakan tingginya kebutuhan masyarakat akan sayur dan buah serta minimnya lahan untuk menumbuhkan tanaman tersebut (Rosliani, 2005; Mas'ud, 2009; Roidah, 2014; (Mas'ud, 2009; Roidah, 2014; Rosliani \& Sumarni, 2005; Wahyuningsih, 2016).

\section{Rosliani \& Sumarni,} menyebutkan bahwa selain memiliki banyak kelebihan, sistem hidroponik juga memiliki beberapa kekurangan dalam pelaksanaannya. Beberapa kekurangan dari sistem hidroponik yaitu: a). Membutuhkan modal yang besar; b). Pada hidroponik dengan pengairan tertutup, peluang tanaman terserang hama atau patogen secara serempak sangat tinggi karena mereka hanya memiliki satu sumber nutrisi yang sama; c). Pengontrolan nutrisi sangat perlu diperhatikan agar tanaman tidak kelebihan pupuk atau sebaliknya.

Kelemahan dari sistem hidroponik tersebut dapat diminimalisir dengan membuat sistem hidroponik menggunakan alternatif lain, yaitu dengan menggunakan sistem botol. Hidroponik sistem botol lebih hemat biaya dan sangat murah. Selain itu sistem hidroponik menggunakan botol bekas tidak bergantung pada sistem tertutup seperti sistem hidroponik lainnya sehingga peluang terpapar patogen serentak akan sangat kecil. Sumber nutrisi juga diberikan pada masingmasing tanaman sehingga dalam sistem botol ini tidak akan terjadi kekurangan nutrisi pada tanaman.

Setelah memberikan penjelasan mengenai hidroponik beserta kelebihan dan kekurangan dari sistem hidroponik, selanjutnya dilakukan demonstrasi bagaimana membuat sistem hidroponik dengan menggunakan botol bekas. Sebelum mempersiapkan botol bekas untuk media tumbuh tanaman hidroponik, terlebih dahulu dipersiapkan media tumbuh untuk menyemai bibit tanaman yang akan dibudidayakan nantinya. Media tumbuh dibuat dengan menggunakan rockwool yang dipotong seukuran $2 \times 2 \mathrm{~cm}$ perbibit tanaman. Bibit tanaman diletakkan pada rockwool yang telah disediakan dan diusahakan selalu dalam keadaan lembab agar bibit tanaman cepat tumbuh dan tidak kekurangan cairan. Bibit tanaman yang digunakan dalam penyuluhan ini adalah bayam dan kangkung karena sayuran ini cukup cepat tumbuh dan mudah untuk dibudidayakan.

Saat bibit bayam dan kangkung sudah mulai tumbuh, selanjutnya dipersiapkan botol bekas sebagai media tumbuh sayuran dengan sistem hidroponik. Botol bekas yang digunakan adalah botol mineral ukuran 1,5 Liter yang dipotong menjadi dua bagian. Setelah botol dipersiapkan dan telah diisi dengan campuran pupuk A dan B yang telah di mix, maka selanjutnya bibit sayuran dapat dipindahkan kedalam botol yang telah disediakan. Satu botol dapat diletakkan 2-3 bibit sayuran untuk mengoptimalkan pengambilan nutrisi oleh tanaman. Nutrisi tanaman bergantung pada air dan pupuk yang diberikan sehingga keseimbangan keberadaan pupuk juga perlu diperhatikan agar tanaman tidak overdosis nutrisi atau sebaliknya kekurangan nutrisi (Rosliani \& Sumarni, 2005).

Hal utama dalam sistem hidroponik ini adalah bagaimana mengatur ketersediaan air bagi tanaman serta bagaimana meramu nutrisi bagi tanaman agar tumbuh optimal (Gibeaut \& Hulett, n.d.; Roidah, 2014). Oleh karena itu, selama masa pertumbuhan tanaman perlu diperhatikan ketersediaan air dan nutrisi bagi tanaman. Takaran yang digunakan untuk pupuk dapat dilihat pada petunjuk penggunaan pada pupuk tersebut. Cara lain yang dapat digunakan untuk mengoptimalkan pertumbuhan tanaman adalah dengan meramu nutrisi sendiri. Untuk meramu nutrisi diperlukan ilmu dan pengalaman sehingga pada tahapan ini hanya menggunakan pupuk sesuai dengan petunjuk penggunaan pupuk yang terdapat dalam kemasan. 


\section{PENUTUP}

Kegiatan sosialisasi dan pelatihan pembuatan tanaman hidroponik menggunakan limbah botol plastik bekas air mineral merupakan salah satu kegiatan pembinaan yang penting dilakukan dalam rangka menangani pekarangan rumah yang sempit. Peralatan yang dibutuhkan mudah, pembuatannya sederhana dan biaya yang dibutuhkan murah. Kegiatan ini menunjang kemandirian warga dalam menangani limbah botol plastik untuk dijadikan produk pot hidroponik yang bermanfaat dan bernilai guna tinggi. Kegiatan ini juga mampu membina dan meningkatkan jiwa kreativitas warga di lingkungan RT. 12.

\section{DAFTAR PUSTAKA}

Barbosa, G., Gadelha, F., Kublik, N., Proctor, A., Reichelm, L., Weissinger, E., ... Halden, R. (2015). Comparison of Land, Water, and Energy Requirements of Lettuce Grown Using Hydroponic vs. Conventional Agricultural Methods. International Journal of Environmental Research and Public Health, 12(6), 68796891.

https://doi.org/10.3390/ijerph12 0606879

Gibeaut, D. M., \& Hulett, J. (1997). Maximal Biomass of Arabidopsis thaliana Using a Simple, Low-Maintenance Hydroponic Method and Favorable Environmental Conditions', 3. Plant Physiol. 115: 317-319

Janda, T., Szalai, G., \& Tari, I. (1999). Hydroponic treatment with salicylic acid decreases the efects of chilling injury in maize (Zea mays L.) plants. Planta. 208: $175-180$

Mas'ud, H. (2009). Sistem Hidroponik dengan Nutrisi dan Media Tanam Berbeda Terhadap Pertumbuhan dan Hasil Selada. Media Litbang Sulteng, 2(2), 131-136.

Perwtasari, B., Tripatmasari, M., \& Wasonowati, C. (2012). Pengaruh Media Tanam dan Nutrisi Terhadap Pertumbuhan dan Hasil Tanaman Pakchoi (Brassica juncea L.) dengan Sistem Hidroponik. Agrovigor Vol. 5 No. 1

Roidah, I. S. (2014). Pemanfaatan Lahan Dengan Menggunakan Sistem Hidroponik. Jurnal Universitas Tulungagung Bonorowo. Vol. 1.No.2 Tahun 2014

Rosliani, R., \& Sumarni, N. (2005). Budidaya Tanaman Sayuran dengan Sistem Hidroponik. Monograf No. 27. Balai Penelitian Tanaman Sayuran: Pusat Penelitian Dan Pengembangan Hortikultura Badan Penelitian Dan Pengembangan Pertanian: Bandung.

Wahyuningsih, A. (2016). Komposisi Nutrisi dan Media Tanam Terhadap Pertumbuhan dan Hasil Tanaman Pakcoy (Brassica rapa L.) Sistem Hidroponik. Jurnal Produksi Tanaman. Vol. 4 No. 8, Desember 2016: 595-601

Wasonowati, C. (n.d.). Meningkatkan Pertumbuhan Tanaman Tomat (Lycopersicon esculentum) dengan Sistem Budidaya Hidroponik. Agrovigor. Vol. 4 No. 1 